Tarbawi: Jurnal Ilmu Pendidikan p-ISSN:1858-1080 | e-ISSN: 2615-6547

Vol. 16, No. 2, Desember 2020, $134-138$

\title{
Pelaksanaan Latihan Tari Kreasi Anak Down Syndrome Berprestasi Tingkat Nasional di SLB Al-Azhar Bukittinggi
}

\author{
Fadillah Putri, Ardisal Ardisal \\ Universitas Negeri Padang \\ E-mail: fadilla14putri@gmail.com
}

\begin{abstract}
Abstrak. Penelitian ini mendeskripsikan tentang pelaksanaan latihan tari kreasi untuk anak down symdrome yang mampu mencapai prestasi sampai ketingkat nasional dalam bidan tari kreasi. Penelitian ini bertujuan untuk melihat bagaimana cara anak downsyndrome belajar menari, cara latihan yang diberikan guru dalam belajar tari dan cara orangtua memberikan dukungan untuk anak berprestasi, kendala yang dihadapi ketika melatih anak belajar tari serta solusi untuk mengatasi kendala yang dihadapi. Penelitian ini menggunakan metode studi kasus dengan pendekatan kualitatif. Data dari penelitian ini ditafsirkan lalu diperoleh maknanya. Subjek dari penelitian ini adalah anak down sydrome $\mathrm{S}$, pelatih tari, guru pendamping dan orangtua anak S. Hasil penelitian ini mengungkapkan tentang pelaksanaan latihan tari kreasi anak down syndrome berprestasi tingkat nasional. Cara anak downsyndrome belajar tari yaitu dengan cara bertahap yaitu pertama dengan cara mendengarkan musik kepada anak, lalu mengajarkan gerakan mulai dari gerakan sulit sampai gerakan yang mudah, dengan cara memberikan nomor dimasing-masing gerakan dan mensinkronkan gerakan dengan musik. Guru dan orangtua selalu memberikan dorongan dan motivasi untuk anak, dengan cara selalu mendampingi anak dalam latihan sampai mengikuti perlombaan sampai ke tingkat nasional dalam cabang tari kreasi. Kendala yang dihadapi pada saat melatih tari anak down syndrome belajar tari adalah konsentrasi anak downsyndrome mudah teralihkan oleh orang lain yang datang, tidak mau dikritik secara langsung, suka merajuk. Solusi untuk mengatasi kendala yang dihadapi dengan cara mencari ruang latihan yang tidak ada orang lain menganggu saat latihan, agar anak lebih fokus, menyalahkan guru pendamping terlebih dahulu sebelum mengkritik anak, membujuk anak dengan sabar dan mengikuti kemauan anak
\end{abstract}

Kata Kunci: Latihan Tari Kreasi, Downsyndrome, Berprestasi

\begin{abstract}
This study discusses the problems that the authors found in SLB Al-Azhar Bukittinggi. This study describes the implementation of creative dance exercises for downsymdrome children who are able to achieve national level achievement in creative dance midwives. This study aims to see how Downsyndrome children learn to dance, how teachers train in learning dance and how parents provide support for high achieving children, the obstacles faced when training children to learn dance and solutions to overcome the obstacles they face. This research uses a case study method with a qualitative approach. The data from this study are interpreted and then the meaning is obtained. The subjects of this study were Downsydrome $S$ children, dance coaches, accompanying teachers and parents of $S$. The results of this study reveal the implementation of the national-level achievement of the dance practice for Down syndrome children with national achievement. The way down syndrome children learn to dance is in a gradual way, first by listening to music to children, then teaching movements ranging from difficult movements to easy ones, by giving numbers for each movement and synchronizing the movements with music. Teachers and parents always provide encouragement and motivation for children, by always accompanying children in training to following competitions up to the national level in the branch of creative dance. The obstacle faced when practicing dance for children with Down syndrome learning to dance is that the concentration of Down syndrome children is easily distracted by other people who come, do not want to be criticized directly, like to sulk. Solutions to overcome the obstacles faced by finding a practice room where no one else interferes with during training, so that the child is more focused, blaming the accompanying teacher before criticizing the child, persuading the child patiently and following the child's wishes.
\end{abstract}

Keywords: Creative Dance Exercise, Down syndrome, Achieving 


\section{PENDAHULUAN}

Pendidikan adalah hal yang sangat penting dalam kehidupan manusia, setiap individu berhak mendapatkan pendidikan untuk mengembangkan diri agar bisa hidup dan mengembangkan kehidupan, pentingnya sebuah pendidikan baik itu untuk anak normal maupun anak berkebutuhan khusus. Pelaksanaan pendidikan terdiri dari pendidikan akademik dan pendidikan non akademik. Pendidikan non akademik ini bisa berupa kesenian tari, seperti tari kreasi. Tari kreasi adalah sebuah tari yang diciptakan melalui perpaduan antara tari tradisional kerakyatan dan tari tradisional klasik, tari kreasi ini tidak hanya gerak yang dikreasikan, tetapi musik, tat arias, dan kostum juga dikreasikan (Chrisyarani and Werdiningtiya 2018). Tari dapat berfungsi sebagai media pengembangan bakat untuk anak sehingga anak bisa mengembangkan bakat dan mampu meraih prestasi dalam bakat yang dia miliki. Prestasi merupakan suatu keberhasilan seseorang dalam mencapai tujuan (Muhibbin 2007). Dalam mencapai prestasi diperlukan latihan yang maksimal untuk memperoleh sebuah prestasi tersebut. Latihan dapat dikatakan sebagai suatu proses berlatih yang sistematis yang dilakuan secara berulang-ulang (Hanafi 2015).

Berdasarkan grantour (penjajakan lapangan), yang penulis laksanakan pada maret 2020, peneliti mendapatkan informasi tentang seorang anak downsyndrome dengan segala keterbatasan yang dia miliki tidak menghambat dia untuk mengukir prestasi sampai ketingkat nasional. Prestasi yang ia raih sampai ketingkat nasional yaitu pada cabang tari kreasi. $\mathrm{S}$ yang berjenis kelamin perempuan yang berusia 21 tahun kelas XI di SLB Al-Azhar Bukittinggi.

Dari hasil wawancara dengan guru ditemukan bahwa ada seorang anak downsyndrome (S) yang memiliki prestasi dibidang tari kreasi. Pada tanggal 20 juli 2017 di SDLBN Manggis Ganting anak S mengikuti seleksi FLS2N ditingkat kota bukittinggi, S meraih juara 1 dan mewakili kota bukittinggi ditingkat provinsi. Kemudian lanjut pada tanggal 9 s.d 12 Agustus tahun 2017 di Hotel rasaki padang, $\mathrm{S}$ mewakili kota bukittinggi untuk mengikuti lomba ditingkat provinsi, $\mathrm{S}$ juga memperoleh juara 1, karena $S$ juara 1 ditingkat provinsi $S$ dipilih untuk mewakili sumatera barat ke tingkat nasional.Lalu pada tanggal 23 s/d 28 September 2017, S mengikuti perlombaan tingkat nasional dan $\mathrm{S}$ memperoleh juara tiga yang dibuktikan dengan hasil-hasil bentuk piala, tropi dan sertifikat. Down syndrome dapat diartikan secara harfiah, syndrome merupakan suatu gejala yang muncul secara bersamasama. Sedangkan kata down diambil dari dokter yang berkebangsaan inggris yang pertamakali menemukan syndrome ini (Rohmadheny 2016). Downsyndrome juga merupakan keterbelakangan fisik dan mental ana yang diakibatkan oleh abnormalitas perkembangan kromosom nomor 21 (Kosasih 2012).

Penelitian ini bertujuan untuk melihat cara anak downsyndrome belajar menari, latihan yang diberikan guru untuk menggembangkan kemampuan anak, dukungan yang diberikan keluarga $\mathrm{S}$ untuk menunjang prestasi S. Untuk mengetahui kendala saat melatih S belajar tari serta mengetahui solusi untuk mengatasi kendala yang dihadapi dalam melatih anak downsyndrome belajar tari. Penelitian ini juga bisa bermanfaat untuk memberikan acuan kepada berbagai pihak dalam mengembangkan potensi yang dimiliki oleh anak down syndrome.

\section{METODOLOGI}

Jenis penelitian ini menggunakan metode studi kasus dengan pendekatan kualitatif . Studi kasus adalah kajian peneltian kualitatif yang rinci dari suatu latar belakang peristiwa tertentu. Studi kasus yang dpergunakan dalam penelitian ini adalah bersifat tunggal, yang menekankan secara mendalam terhadap beberapa kasus yang sedang diteliti (Afrianto 2016).

Tempat penelitian ini dilakukan adalah di SLB AL-Azhar Bukittinggi, dirumah pelatih tari anak S. Sumber data utama dalam penelitian ini adalah anak downsyndrome $\mathrm{S}$ di slb al-azhar bukittinggi, sedangkan data pendukungnya adalah orantua anak downsyndrome $\mathrm{S}$, pelatih tari dan guru yang mendampingi dalam latihan tari sampai ketingkat nasional. Penelitian ini dilakukan selama 1 bulan 
mulai dari bulan oktober sampai november. Penelitian ini dilakukan kepada anak downsyndrome kelas XI.

Teknik pengumpulan data yang dilakukan oleh penulis adalah dengan cara pengamatan langsung kelapangan, untuk memperoleh data langsung yang diperlukan melalui observasi, wawancara dan studi dokumentasi. Alat yang digunakan untuk mengumpulkan data adalah dengan menggunakan instrumen yang berkaitan dengan pertanyaan penelitian yang sudah dibuat sendiri oleh penulis dan member tanda ceklis pada pengumpulan data

Penulis mengolah data dengan cara mencatat hasil pengamatan yang dilakukan dengan teknik wawancara, observasi dan studi dokumentasi dalam bentuk catatan lapangan. Setelah dipilahpilah, lalu ditafsirkan serta mengarahkan dan membuang hal yang tidak perlu, setelah data ditafsirkan, lalu diperoleh maknanya. Kemudian mengklasifikasikan data-data yang sudah diperoleh untuk disesuaikan dengan fokus penelitian yang ada, serta mengelompokkan data sesuai dengan fokus penelitian. Selanjutnya menganalisis data yang sudah terkumpul untuk diolah. Terakhir menarik kesimpulan yaitu menganaslisis data yang ditemukan telah teroganisasi dalam bentuk pertanyaan, kalimat yang singkat dan padat, namun mengandung art yang luas tentang Pelaksanaan Latihan Tari Kreasi Anak Downsyndrome Berprestasi Tingkat Nasional Di SLB Al-Azhar Bukittinggi.

\section{TEMUAN}

Berdasarkan studi pendahuluan cara anak downsydrome belajar menari, cara latihan yang diberikan guru dalam mengembangkan kemampuan anak, bentuk dukungan yang diberikan orangtua dan keluarga, diantaranya yaitu:Cara anak belajar menari yang pertama yaitu memperkenalkan musik terlebih dahulu kepada anak, apakah anak nyaman dengan musiknya. Setelah anak tau dengan musik, lalu anak diajarkan gerakan, mulai dari gerakan yang paling sulit sampai gerakan paling mudah yang diajarkan kepada anak dengan cara anak melihat gerakan yang dicontohkan oleh pelatih terlebih dahulu. Masing-masing gerakan yang diajarkan oleh pelatih diberi nomor agar memudahkan anak untuk mengingat dan untuk menyusun gerakan tersebut nantiknya. Setelah anak mendapatkan 2 sampai 3 gerakan, maka langsung disinkronkan dengan musik dan menyusun gerakan yang sudah diajarkan tadi.

Fasilitas yang diberikan sekolah untuk mengembangkan kemampuan yang dimiliki $\mathrm{S}$ adalah dengan cara mendatangkan pelatih dari luar untuk melatih $S$ menari, selain itu sekolah juga mencukupi kebutuhan S mulai dari konsumsi, transportasi, dan pakaian untuk menari. Latihan dilakukan 3 bulan sebelum mengikuti perlombaan, jadwal latihan tidak menentu bisa dalam 1 minggu latihannya setiap hari, bisa juga dalam 1 minggu itu hanya 3 kali saja, setiap kali latihan waktunya hanya 1-2 jam paling lama. Latihan dilaksanakan diruang kantor majlis guru atau diteras sekolah. Metode yang digunakan guru dan pelatih adalah dengan metode demonstrasi dan metode imitasi.

Kemudian dukungan yang diberikan oleh keluarga $S$ sangat menunjang prestasinya, dengan cara selalu memberikan support dan semangat untuk S. Terutama mamanya yang selalu mendampingi $\mathrm{S}$ saat latihan tari dan menemani $\mathrm{S}$ untuk mengikuti perlombaan tari mulai dari tingkat kota, provinsi dan nasional. Dukungan yang diberikan keluarga penuh untuk S sehingga membuat $\mathrm{S}$ merasa percaya diri dan mampu berkembang dalam meraih prestasinya. Kendala yang dihadapi pada saat melatih tari anak down syndrome belajar tari adalah konsentrasi anak downsyndrome mudah teralihkan oleh orang lain yang datang, tidak mau dikritik secara langsung, suka merajuk. Solusi untuk mengatasi kendala yang dihadapi dengan cara mencari ruang latihan yang tidak ada orang lain menganggu saat latihan, agar anak lebih fokus, menyalahkan guru pendamping terlebih dahulu sebelum mengkritik anak, membujuk anak dengan sabar dan mengikuti kemauan anak

\section{DISKUSI}


Dibalik kekurangan yang dimiliki oleh anak downsyndrome, juga banyak kelebihan yang dimiliki oleh anak downsyndrome ini, salah satunya yaitu kemampuan menari. Dimana didalam diri anak downsydrome $S$ ini memiliki bakat untuk menari sehingga pihak sekolah pun membantu dengan cara memberikan fasilitas untuk S belajar menari, sehingga $S$ mampu berprestasi sampai ketingkat nasional. Pada umumnya orang yang berprestasi adalah seseorang yang mampu mengoptimalkan potensi yang dimilikinya secara efektif dan efisien. Prestasi merupakan hasil yang telah dicapai dari apa yang sudah dilakukan, dikerjakan dan sebagainya(Julianto 2019).

Dalam mencapai sebuah prestasi dibidang tari tentu diperlukan kerja keras dan latihan terlebih dahulu. Ada lima komponen yang menentukan keberhasilan dalam pelaksanaan latihan tari yaitu yang pertama pengajar merupakan orang yang akan mengajarkan, yang kedua ada siswa yang merupakan subjek yang akan menerima pembelajaran, yang ketiga ada materi pelajaran dan kurikulum, yang keempat ada pelaksanaan atau jadwal kegiatan pembelajaran dan yang terakhir ada evaluasi pembelajaran (Priyanto 2005).

Cara latihan yang diberikan untuk anak S sangat efektif, karena latihan yang diberikan oleh pelatih dan guru pendamping sudah sesuai dengan kemampuan anak. Anak S ini sudah memiliki bakat dalam menari sehingga dengan diberikan latihan bakat tersebut mampu berkembang. Cara latihan dengan mendengarkan dan memperkenalkan music terlebih dahulu untuk anak membuat anak tersebut nyaman dengan musik, mengajarkan gerakan sulit terlebih dahulu dilakukan karena penghafalan gerakan sulit ini memakan waktu untuk anak mengingatnya, setelah anak mendapatkan gerakan sulit diberikan gerakan mudah yang akan cepat diingat oleh anak. Untuk memudahkan anak menyinkronkan gerakan dengan musik maka pelatih memberikan penomoran dimasing-masing gerakan sehingga hal tersebut memudahkan nantinya ketika anak $\mathrm{S}$ sudah disuruh menari dengan diiringi musik, hanya dengan menyebutkan nomor gerakan saja, misalkan masuk ke gerakan 1, masuk ke gerakan 3 dan seterusnya.

Dukungan orangtua sangatlah penting untuk menunjang prestasi dan keberhasilan anak dimasa depan. Dukungan orangtua merupakan suatu upaya yang diberikan oleh orang tua kepada anaknya, baik itu dukungan moril maupun materil, untuk memotivasi anak agar semangat dalam melakukan sesuatu kegiatan (Iswari 2019). Guru juga memiliki peran yang cukup besar dalam keberhasilan seorang anak. Guru juga berperan penting dalam membantu perkembangan peserta didik untuk mewujudkan tujuan hidup secara optimal. Minat, bakat, kemampuan dan potensipotensi yang dimiliki anak tidak akan berkembang secara optimal tanpa bantuan guru (Salminawati 2016).

Kendala pada saat latihan ini terjadi karena mudahnya kosentrasi anak down syndrome teralihkan, tidak sukanya anak down syndrome dikritik secara langsung dan mudah merajuk, hal ini merupakan karakteristik dari anak down syndrome. Sehingga untuk mengatasi kendala pelatih mencari ruangan lain yang tidak akan ada tamu yang datang sehingga fokus anak tidak teralihkan dan hanya fokus dengan latihan, lalu ketika anak salah maka yang dikritik adalah gurunya dan yang disalahkan adalah gurunya sehingga anak merasa dirinya tidak salah dan anak tetap mau mengikuti latihan dan membujuk anak ketika anak merajuk atau sedang tersingung dengan cara mengikuti kemauan anak agar anak tetap mau mengikuti latihan.

\section{PENUTUP}

Latihan yang dilakukan pelatih dan guru pendamping untuk melatih tari anak adalah dengan cara mendengarkan musik terlebih dahulu, setelah anak nyaman dengan musik, lalu masuk ke tahap mengajarkan gerakan, gerakan yang diajarkan awal yaitu gerakan sulit, baru gerakan mudah dengan cara memberikan nomor dimasing-masing gerakan untuk memudahkan saat penyusunan gerak, setelah anak dapat menguasi 2-3 gerakan, maka langsung disinkronkan dengan musik yang sudah didengar anak tadi. Metode yang dilakukan pelatih dan guru untuk latihan tari anak adalah dengan 
metode demonstrasi dan metode imitasi. Dukungan yang diberikan oleh keluarga S sangat menunjang prestasinya, dengan cara selalu memberikan support dan semangat untuk S. Terutama mamanya yang selalu mendampingi $S$ saat latihan tari dan menemani $S$ untuk mengikuti perlombaan tari mulai dari tingkat kota, provinsi dan nasional. Dukungan yang diberikan keluarga penuh untuk $\mathrm{S}$ sehingga membuat $\mathrm{S}$ merasa percaya diri dan mampu berkembang dalam meraih prestasinya. Kendala yang dihadapi pada saat melatih tari anak down syndrome belajar tari adalah konsentrasi anak downsyndrome mudah teralihkan oleh orang lain yang datang, tidak mau dikritik secara langsung, suka merajuk. Solusi untuk mengatasi kendala yang dihadapi dengan cara mencari ruang latihan yang tidak ada orang lain menganggu saat latihan, agar anak lebih fokus, menyalahkan guru pendamping terlebih dahulu sebelum mengkritik anak, membujuk anak dengan sabar dan mengikuti kemauan anak.

\section{REFERENSI}

Afrianto. 2016. Implementasi Metode Studi Kasus Dengan Pendekatan Kualitatif. Jakarta: PT Rineka Cipta.

Chrisyarani, Denna Delawanti \&., and Ratih Kartika Werdiningtiya. 2018. "Pelatihan Seni Tari Kreasi Baru Bagi Guru SD Di Kecamatan Jabung Kabupaten Malang." JPM (Jurnal Pemberdayaan Masyarakat) 3(1).

Hanafi, S. 2015. "Hubungan Motor Fitness Dengan Keterampilan Bermain Bola Voli Fazlullah." ILARA (2):32-35.

Iswari, Mega \&. Bunga Shashilya Tanjung. 2019. "Dukungan Orangtua Terhadap Prestasi Anak Tunanetra Disekolah Inklusi."

Julianto, Teguh \&. Arief Husin. 2019. "Pengembangan Desain Pembelajaran Kreatif-Produktif Dalam Pembelajaran Biologi Terhadap Pencapaian Aktivitas Kognitif Siswa SMA Di Kabupaten Banyumas." Journal of Chemical Information and Modeling 53(9):1689-99.

Kosasih, E. 2012. Cara Bijak Memahami Anak Berkebutuhan Khusus. Bandung: Yrama widya.

Muhibbin, Syah. 2007. Psikologi Pendidikan Dengan Pendekatan Baru. Bandung: Remaja Rosda Karya.

Priyanto, Wien Pudji. 2005. "Pembelajaran Tari Kreasi Baru Di Padepokan Seni Bagong Kussudiardja (PSBK) Yogyakarta."

Rohmadheny, Prima Suci. 2016. "Studi Kasus Anak Downsyndrome Case Study of Down Syndrome Child." Jurnal CARE (Children Advisory Research and Education).

Salminawati. 2016. Filsafat Pendidikan Islam. Bandung: Cita Pustaka Media Perintis. 